\title{
ISSR-BASED POPULATION GENETICS STUDY FOR TAGGING A DIVERSE POPULATION OF SHISHAM (DALBERGIA SISSOO) IN PAKISTAN
}

\author{
IJAZ, S. $.^{*}-$ UL HAQ, I. $^{2}-$ RAZZAQ, H. A. ${ }^{1}-$ NASIR, B. ${ }^{1}-$ BABAR, M. ${ }^{1}$ \\ ${ }^{I}$ Centre of Agricultural Biochemistry and Biotechnology (CABB), University of Agriculture, \\ University Road, Faisalabad, Pakistan \\ ${ }^{2}$ Department of Plant Pathology, University of Agriculture, University Road, Faisalabad, \\ Pakistan \\ *Corresponding author \\ e-mail: siddraijazkhan@yahoo.com; phone: +92-333-166-1795
}

(Received $14^{\text {th }}$ Jan 2019; accepted $26^{\text {th }}$ Feb 2019)

\begin{abstract}
Population genetics is a subject of modelling the variations in gene and allele frequencies resulting genetic diversity between and within the population. The molecular marker assisted approaches in juxtaposition to computational biology have become powerful tools to explore the genetic pattern and diversity of a particular population. Therefore, population genetics of shisham population in terms of their diversity and genetic pattern was investigated. Twenty-one ISSR markers were used to investigate 30 shisham genotypes collected from Sindh, KPK and Balochistan. Genetic diversity analysis showed 337 loci were amplified with percent polymorphic loci, 99.41. Maximum diversity was found between genotypes SKP3 and KPK P3, however, genotypes TTP1 \& TTP2 was found to be more similar. Principal Coordinate analysis depicted, first II coordinates accounted for $40.69 \%$ total genetic variation in 2-D plotting. AMOVA predicted high level of percent genetic variance within population $(99 \%)$. Population genetic structure prediction using admixture model of Bayesian inference showed selected shisham population shared three gene pools $(\mathrm{K}=3)$, with diverse genetic pattern that were grouped as distinct or even sharing maximum genetics. These findings could either be helpful for tagging and shaping scattered shisham population of Pakistan or a practical step toward identifying dieback disease resistant shisham germplasm.
\end{abstract}

Keywords: molecular characterization, macropropagation, genetic structure, genetic diversity, dendrogram

\section{Introduction}

Population genetics of trees is an imperative approach for characterizing, conserving and improving their dispersed population in a well-arranged manner. Evolutionary processes are the fundamental forces, which bring heterogeneity, existed in trees population. For exploring the forest biodiversity, their genetic study using molecular markers is of great impact (Tereba et al., 2017). Molecular markers have been employing to evaluate the genetic diversity based on allelic frequency present between and among the tree species (Zaya et al., 2017). These markers with the aid of computational biology well describe the genetic relationship of population at species as well as cultivar levels. These DNA markers, which determine the genetic relatedness in terms of diversity without environmental influence, are ISSR (Inter Simple Sequence Repeat), SSR (Simple Sequence Repeat), RAPD (Randomly Amplified Polymorphic DNA) etc. However, inter-SSR markers were identified as new and technically simple molecular marker technique that with small DNA template give results with robust and excellent repeatability (Nilkanta et al., 2017; Sheng et al., 2017). 
Therefore, for determining the genetic diversity of Dalbergia sissoo (Shisham, tali) population of Sindh, KPK and Balochistan, ISSR marker analysis was made. Due to the fact that Dalbergia sissoo is economically the most important timber tree in Asia (Subedi et al., 2017). However, there is no well-defined categorization of its existed genotypes. Hence, ISSR based identification and tagging of diverse population of shisham from Punjab (Pakistan) has been attempted by Ijaz et al. (2018). In Dalbergia species SSR markers are not available, and characterization of shisham population in other countries has been documented using RAPD and ISSR markers (Bal and Panda, 2018). As literature supports that ISSR markers reveals high polymorphism rate with more reliability in comparison to RAPD markers (Wu et al., 2018), ISSR markers were used to study population genetics of shisham collected from Sindh, KPK and Balochistan (Pakistan).

\section{Materials and methods}

\section{Germplasm collection and macropropagation}

For the collection of healthy shisham germplasm, surveys were conducted across the three provinces of Pakistan viz., Sindh, KPK and Balochistan. Branch cuttings (3-5) were taken from healthy shisham trees and placed in differently labelled sampling bags. The selected shisham population size remained 15 from Sindh, 10 from KPK and 5 from Baluchistan (Table 1). Sandy loam soil was used to fill polythene bags (5-7" in length) after sterilization with $37 \%$ formalin solution. Cuttings from shisham trees (7$9 \mathrm{~cm}$ ) with 3-5 nodes were planted in soil filled polythene bags and kept in green house for macropropagation (Fig. 1).

Table 1. List of shisham genotypes collected from three provinces (Sindh, KPK and Balochistan) Pakistan

\begin{tabular}{|c|c|c|c|c|}
\hline Sr. \# & Region & Plant code & Sr.\# & Plant code \\
\hline \multirow{2}{*}{\multicolumn{3}{|c|}{ Sindh }} & \multicolumn{2}{|c|}{ Khyber Pakhtunkhwa (KPK) } \\
\hline & & & 1. & KPK P1 \\
\hline 1. & \multirow{3}{*}{ Hyderabad } & HP1 & 2. & KPK P2 \\
\hline 2. & & HP2 & 3. & KPK P3 \\
\hline 3. & & HP3 & 4. & KPK P4 \\
\hline 4. & \multirow{3}{*}{ Jamshoro } & JSP1 & 5. & KPK P5 \\
\hline 5. & & JSP2 & 6. & KPK P6 \\
\hline 6. & & JSP3 & 7. & KPK P7 \\
\hline 7. & \multirow{2}{*}{ Khairpur } & KPP1 & 8. & KPK P8 \\
\hline 8. & & KPP2 & 9. & KPK P9 \\
\hline \multirow{2}{*}{$\begin{array}{c}9 . \\
10 .\end{array}$} & \multirow{2}{*}{ Naushahro Feroze } & NFP1 & 10. & KPK P10 \\
\hline & & NFP2 & \multicolumn{2}{|c|}{ Balochistan } \\
\hline 11. & \multirow{3}{*}{ Sukkur } & SKP1 & 1. & BLP1 \\
\hline 12. & & SKP2 & 2. & $\mathrm{BP} 2$ \\
\hline 13. & & SKP3 & 3. & BLP3 \\
\hline 14. & \multirow{2}{*}{ Thatta } & TPP1 & 4. & BLP4 \\
\hline 15. & & TPP2 & 5. & BLP5 \\
\hline
\end{tabular}




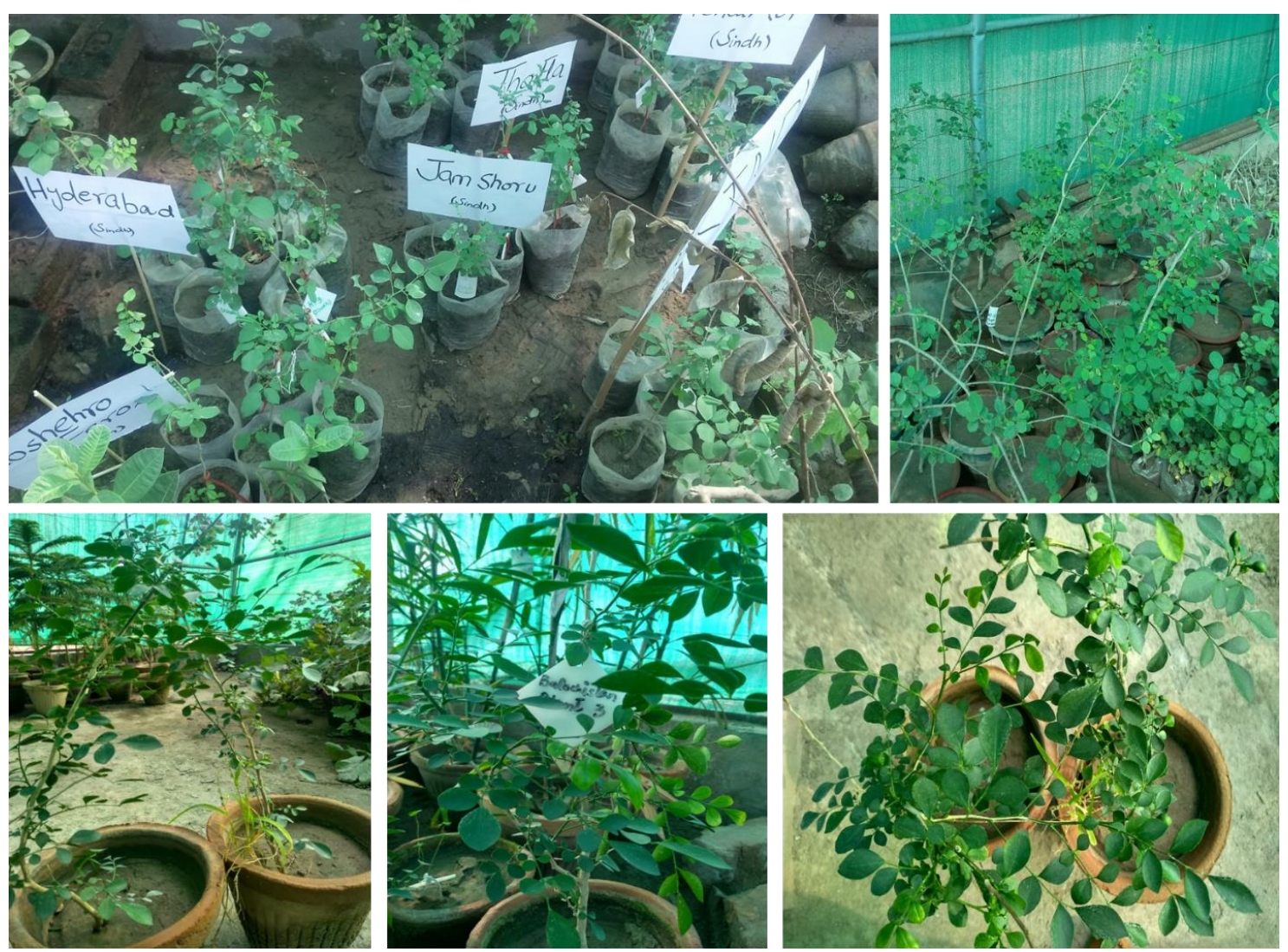

Figure 1. Macropropagated shisham germplasm collected from Sindh, KPK and Balochistan at green house of Fungal Molecular Biology Laboratory (FMB Lab.), Department of Plant Pathology, University of Agriculture Faisalabad, Punjab, Pakistan

\section{Molecular analysis}

DNA of selected samples was isolated using modified CTAB method (Ijaz et al., 2018). Twenty one (21) ISSR markers were used for the amplification using PCR reaction conditions described by Ijaz et al., 2018. Polymerase Chain Reaction was performed on 96 well thermal cycler (peq STAR). The PCR products were resolved on agarose gel (2.5\%) and visualized on gel documentation system (Bio Rad, USA). Band counting was scored as "1", for presence and " 0 " for absence on excel sheet. Data was analyzed using different software packages (STRUCTURE v. 2.3.4, PopGen 32 v. 1.32, PAST v. 3.16, DARwin6 v. 6.0, GenAlExe v. 6.501 and Power Marker v. 3.25) available for genetic diversity and population genetics studies.

\section{Results}

ISSR marker based PCR products with reliability of DNA bands (depending on SSR motifs) were obtained (Fig. 2). In three province of Pakistan, these 21 ISSR markers amplify 337 loci in total among 30 selected shisham genotypes, of which recorded polymorphism percentage was 99.41 accounted for 335 polymorphic loci. Total amplified alleles were 5252 that ranging from 57 (ISSR-17) to 321 (ISSR-5), while an average alleles per primer were 250.09. However, average number of alleles per locus ranged as 10.28 (ISSR-14) to 21.89 (ISSR-9). The high level polymorphism was 
exhibited from 8.60 (ISSR-15) to 18.61 (ISSR-14). To check marker diversity PIC (Polymorphic Information Content) was calculated, that ranged from 0.2493 (ISSR-14) to 0.4321 (ISSR-1) with average of 0.3435 . However, the calculated value for gene diversity was ranged 0.3045 (ISSR-14) to 0.4986 (ISSR-1) with mid value of 0.4142 (Table 2).

\section{Genetic diversity analysis}

Genetic diversity was performed using two distance matrix based clustering analyses i.e. unweighted pair group method with arithmetic mean (UPGMA) based dendrogram using PAST v.3.16 (Euclidean matrices) and Unweighted Neighbor-Joining (NJ) based dendrogram using DARwin6 (bootstrap method). The UPGMA based hierarchical clustering of 30 shisham genotypes showed four major clusters (I, II, III \& IV) (Fig. 3). The cluster I comprised of KPK genotypes, KPK P3, KPK P4, KPK P5, KPK P6, KPK P7, KPK P8, KPK P9 \& KPK P10 (KPK genotypes). Cluster II, being the largest, included Sindh genotypes, TTP1 \& TTP2 (Thatta genotypes), HP1, HP2 \& HP3 (Hyderabad genotypes), NFP1 \& NFP2 (Naushahro Feroze genotypes), KPP1 \& KPP2 (Khairpur genotypes), JSP1, JSP2 \& JSP3 (Jamshoro genotypes), SKP1 \& SKP2 (Sukkur genotypes). Balochistan genotypes, BLP1, BLP2, BLP3, BLP4 \& BLP5 were grouped in cluster III. While cluster IV was observed to be distinct one which comprised of KPK P1, KPK P2 (KPK genotypes) and SKP3 (Sukkur genotype, Sindh). The whole dendrogram was rooted by the three genotypes of cluster IV. Despite this dendrogram, Neighbor Joining (NJ) based clustering (using Darwin6 software) with 1000 bootstraps, also supported the UPGMA results (Fig. 4). Somehow, same clustering pattern was observed among selected genotypes of three provinces which validated the results as well.

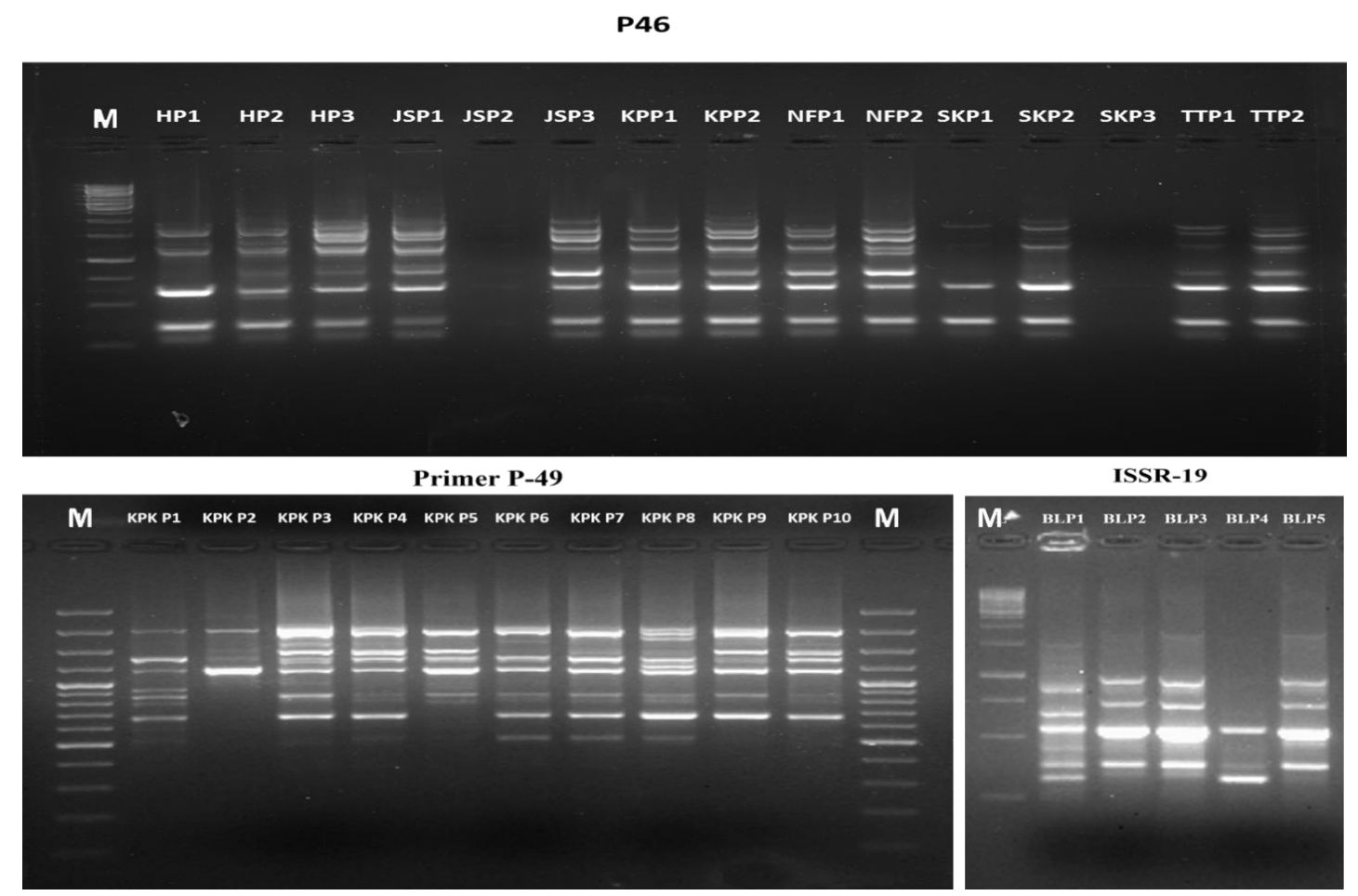

Figure 2. PCR amplification of shisham genotypes collected from Sindh, KPK and Balochistan using ISSR primers. ( $M=1 \mathrm{~kb}$ DNA ladder $)$ 
Table 2. The number of scored bands and marker informativeness of 21 selected ISSR primers

\begin{tabular}{c|c|c|c|c|c|c|c|c}
\hline Sr.\# & $\begin{array}{c}\text { Primers } \\
\text { (Ijaz et al., 2018) }\end{array}$ & $\begin{array}{c}\text { No. of } \\
\text { loci }\end{array}$ & $\begin{array}{c}\text { Total no. } \\
\text { of allele }\end{array}$ & $\begin{array}{c}\text { No. of alleles } \\
\text { per locus }\end{array}$ & $\begin{array}{c}\text { Total polymorphic } \\
\text { allele }\end{array}$ & $\begin{array}{c}\text { Polymorphism } \\
\text { (\%) }\end{array}$ & PIC* & EGD** \\
\hline 1 & P-46 & 15 & 269 & 17.93 & 166 & 11.06 & 0.3539 & 0.4229 \\
2 & P-49 & 16 & 253 & 15.81 & 227 & 14.19 & 0.3209 & 0.4109 \\
3 & ISSR-1 & 17 & 221 & 13 & 238 & 14 & 0.4321 & 0.4986 \\
4 & ISSR-2 & 14 & 198 & 14.14 & 208 & 14.85 & 0.3333 & 0.3987 \\
5 & ISSR-3 & 15 & 170 & 11.33 & 250 & 16.67 & 0.3912 & 0.4571 \\
6 & ISSR-4 & 18 & 236 & 13.11 & 304 & 16.89 & 0.2985 & 0.3782 \\
7 & ISSR-5 & 17 & 321 & 18.88 & 189 & 11.12 & 0.3281 & 0.4215 \\
8 & ISSR-6 & 18 & 283 & 15.72 & 221 & 12.28 & 0.4126 & 0.4845 \\
9 & ISSR-7 & 20 & 250 & 12.5 & 310 & 15.5 & 0.3866 & 0.4511 \\
10 & ISSR-8 & 21 & 330 & 15.71 & 258 & 12.28 & 0.3646 & 0.4205 \\
11 & ISSR-9 & 18 & 394 & 21.89 & 110 & 6.47 & 0.2972 & 0.3316 \\
12 & ISSR-10 & 18 & 297 & 16.5 & 225 & 12.5 & 0.3505 & 0.4224 \\
13 & ISSR-11 & 18 & 379 & 21.05 & 161 & 8.94 & 0.2894 & 0.3598 \\
14 & ISSR-12 & 18 & 328 & 18.22 & 212 & 11.78 & 0.3110 & 0.3970 \\
15 & ISSR-13 & 15 & 193 & 12.87 & 242 & 16.13 & 0.3255 & 0.3850 \\
16 & ISSR-14 & 18 & 185 & 10.28 & 335 & 18.61 & 0.2493 & 0.3045 \\
17 & 1SSR-15 & 15 & 309 & 20.6 & 129 & 8.6 & 0.3288 & 0.3930 \\
18 & ISSR-16 & 15 & 193 & 12.87 & 242 & 16.13 & 0.3725 & 0.4567 \\
19 & ISSR-17 & 4 & 57 & 14.25 & 59 & 14.75 & 0.3871 & 0.4733 \\
20 & ISSR-18 & 12 & 164 & 13.67 & 172 & 15.64 & 0.3442 & 0.4 \\
21 & ISSR-19 & 15 & 222 & 14.8 & 228 & 15.2 & 0.3370 & 0.4325 \\
\hline & Total & 337 & 5252 & 325.13 & 4486 & --- & 7.2143 & 8.6998 \\
\hline & Average & --- & 250.09 & --- & --- & 13.504 & 0.3435 & 0.4142 \\
\hline
\end{tabular}

*Polymorphic information contents. **Expected gene diversity

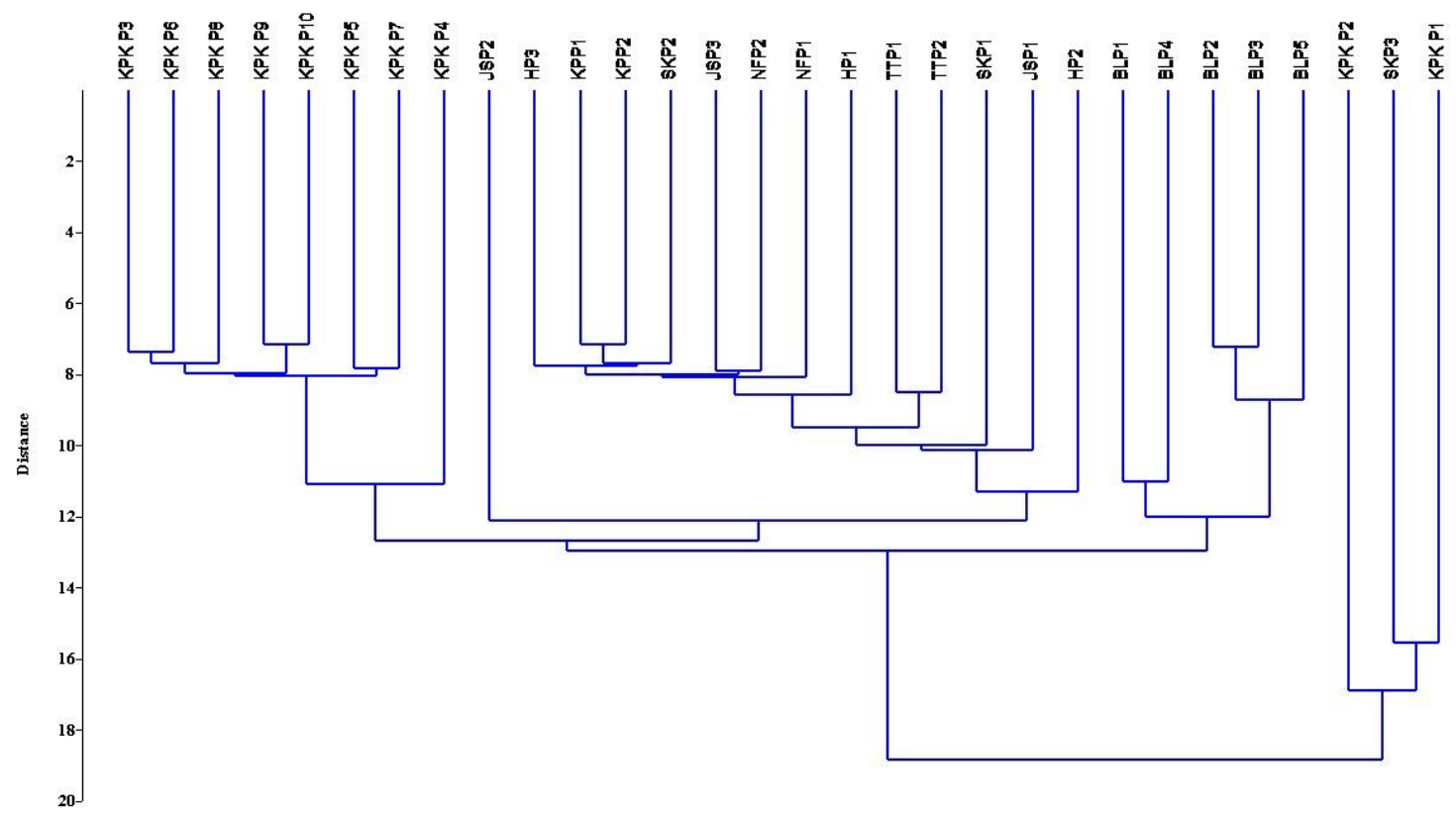

Figure 3. A UPGMA dendrogram based on Nei's genetic distance, showing clustering of 30 shisham samples collected across Sindh, KPK and Balochistan (Pakistan) 


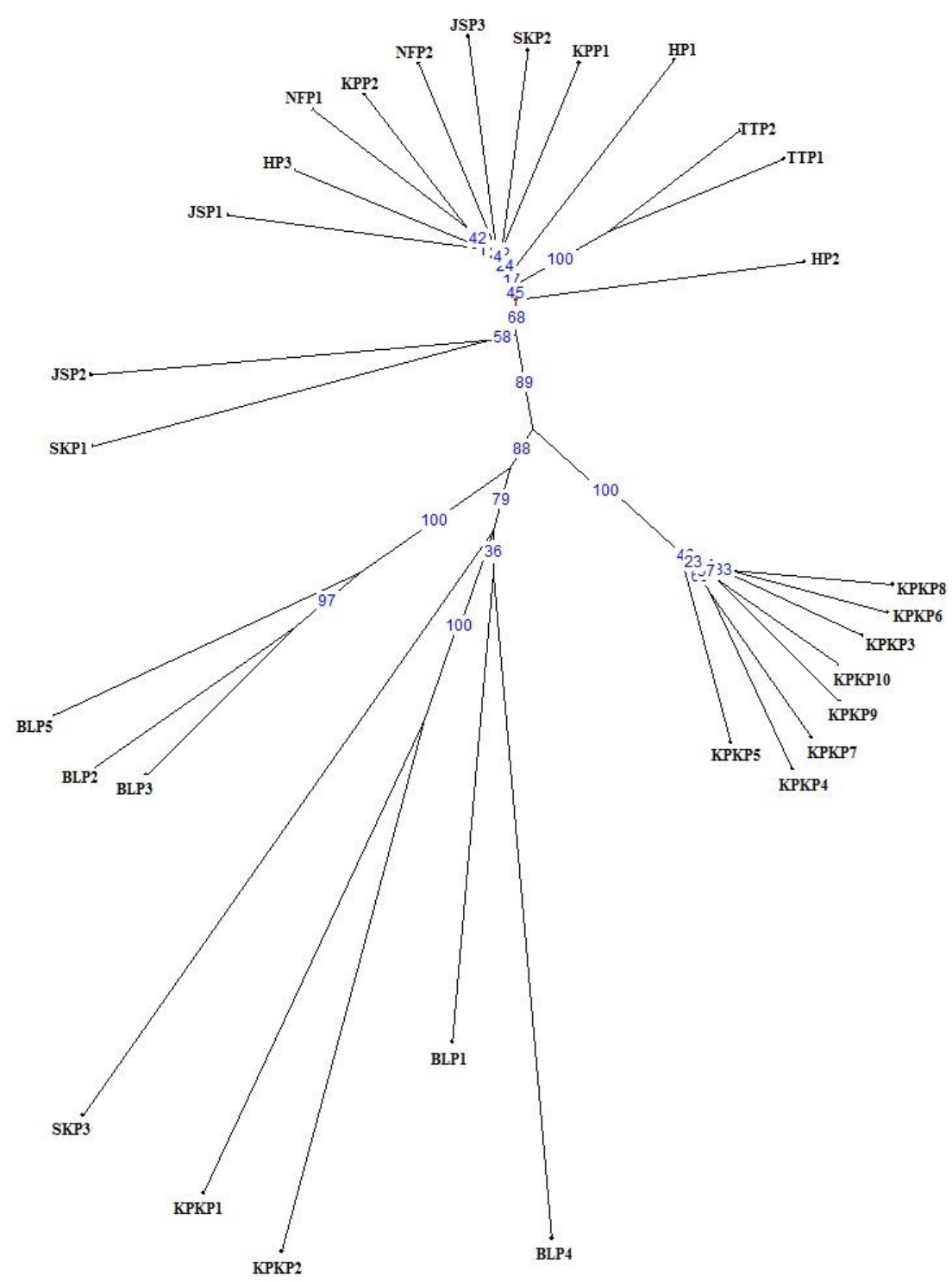

Figure 4. A dendrogram using DARwin6 software, based on unweighted neighbor joining (NJ), showing hierarchical clustering of 30 representative shisham genotypes from three provinces, Pakistan.

The similarity index retrieved from PopGen 32 also corelated with the results of dendrogram. The overall Nei's genetic distance ranged from 0.1594 to 1.1168 . The maximum Nei's genetic diversity value of 1.1168 was scored by SKP3 and KPK P3 genotypes. Moreover, Sukkur genotype (SKP3) showed diversity value of 1.0197 and 1.0104 with KPK genotypes, KPK P6 and KPK P8, respectively. However, Thatta genotypes (TTP1 \& TTP2) scored least Nei's genetic diversity value of 0.1594 . These diversity values and the cladding of 30 genotypes were in accordance to each other. In addition, the values for total genetic diversity $\left(\mathrm{H}_{\mathrm{t}}\right)$, number of alleles (na), effective number of alleles (ne), Nei's gene diversity (h) and Shannon's information index (I) was also computed by PopGen32. The values for $\mathrm{H}_{\mathrm{t}}$ 0.3705, na 1.9941, ne 1.6487, $\mathrm{h}$ 0.3705 and I 0.5469 were recorded on an average with standard deviation of 0.0169 , $0.0769,0.2968,0.1301$ and 0.1580 , respectively. 
Principle Coordinate Analysis (PCoA) was executed on Darwin6 program package to determine the spatial representation among and within selected shisham population based on genetic differences (Fig. 5). These results were in concurrence to the UPGMA based and NJ based clustering of selected genotypes. The two dimensional (2-D) plotting of 30 genotypes were observed from three provinces. These results revealed that first two coordinates (coords) accounted for genetic variation, 21.62\% (Coord I) and $19.07 \%$ (Coord II). The genotypes found in intermixed as well as in scattered form. The SKP1, SKP3 (Sukkur genotypes, Sindh) and JSP2 (Jamshoro genotype, Sindh), BLP1, BLP2, BLP3, BLP4, BLP5 (Balochistan genotypes) KPK P1, KPK P2 (KPK genotypes) were showed to be scattered while all other genotypes were more or less closely related.

Factorial analysis: (Axes 1/2)

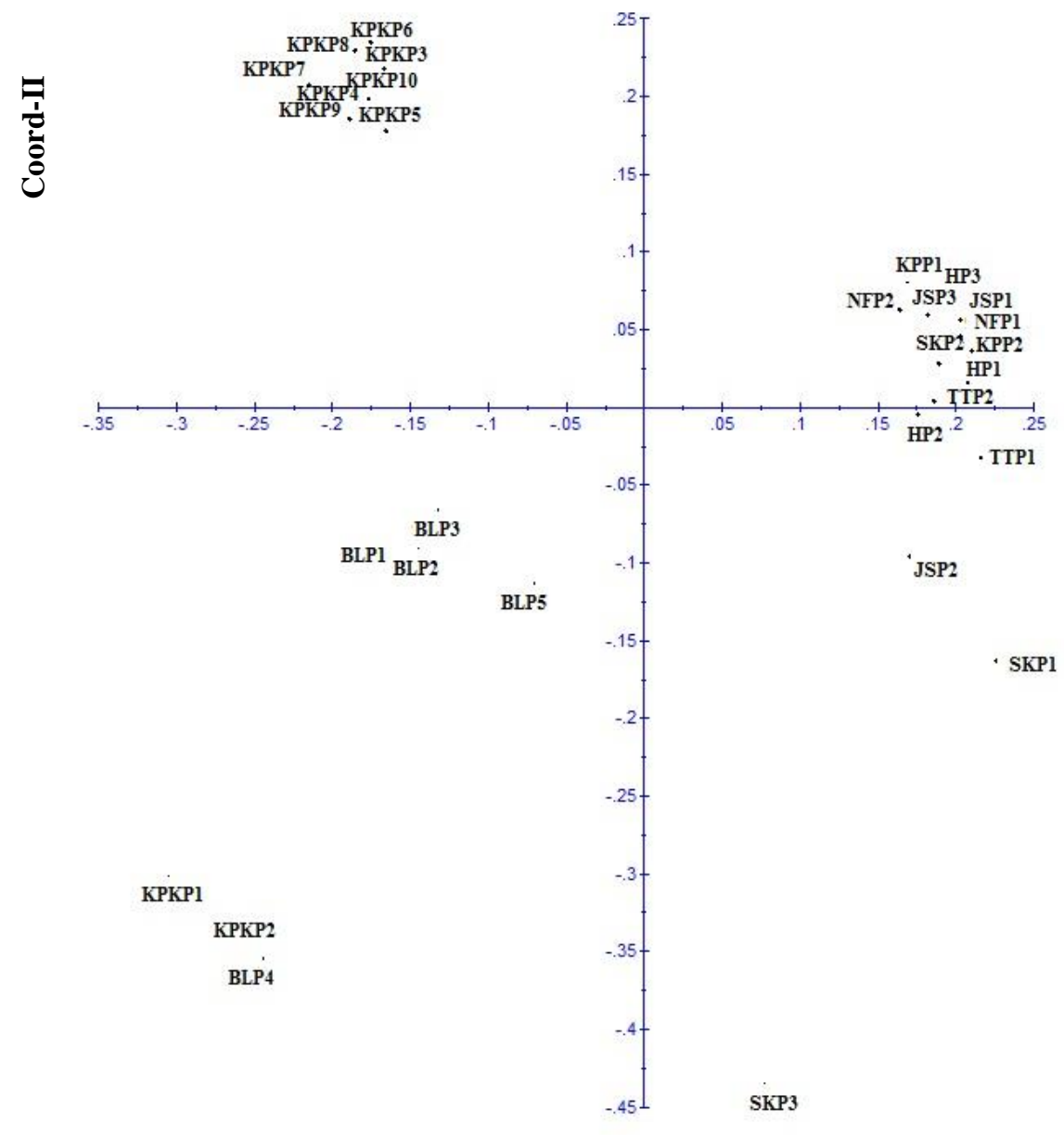

Coord-I

Figure 5. PCoA based 2-D plot of 30 shisham genotypes from Sindh, KPK and Balochistan, Pakistan

Analysis of molecular variance analysis (AMOVA) was performed using MS-Excel based program GenAlExe, on the whole ISSR data score of shisham genotypes without grouping by region or geographical location (Table 3 ). This analysis was performed to 
understand the relationships within and among the populations (Fig. 6). AMOVA revealed high percentage credited to intra-population variation $(99 \%)$ while the remaining in inter-population variation $(1 \%)$. Therefore, in total, proportion of variation among shisham populations of three provinces was lower than within the populations, suggesting the collected shisham genotypes are highly diverse to each other but of same origin.

Table 3. Calculated variance for inter and intra populations with percent of the variance of each source to the total variance

\begin{tabular}{c|c|c|c|c|c}
\hline Source & Degree of freedom (df) & Sum of square (SS) & Mean sum of square (MS) & Est. var. & Var. \% \\
\hline Among pops & 2 & 185.800 & 92.900 & 1.032 & $1 \%$ \\
Within pops & 27 & 2253.000 & 83.444 & 83.444 & $99 \%$ \\
\hline Total & 29 & 2438.800 & & 84.476 & $100 \%$ \\
\hline
\end{tabular}

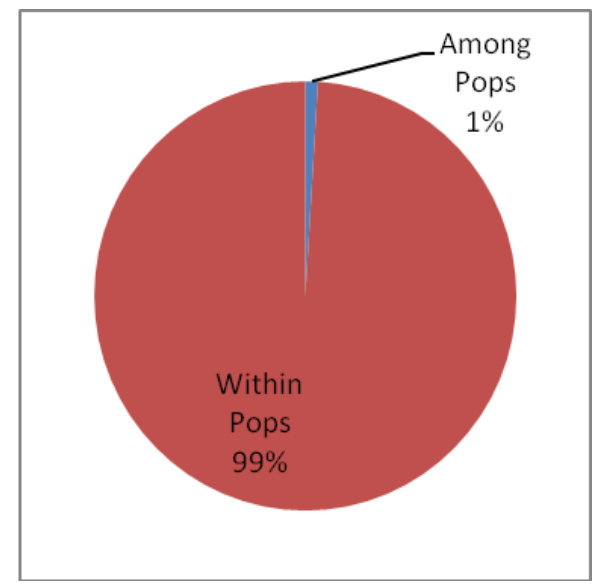

Figure 6. Percentile of molecular variance among and within studied shisham populations

\section{Population genetic structure}

The pattern of genetic structure among shisham population among three provinces has been observed using computer program STRUCTURE. The STRUCTURE HARVESTER suggested shisham population into appropriate subpopulation (K). The K was set from 2-5 with 10,000 burn-in and MCMC. Whereas the estimation of subpopulations was done by delta $K(\Delta K)$ value. For selected genotypes from three provinces (30 genotypes) the $\Delta \mathrm{K}$ value was recorded as highest at $\mathrm{K}=3$, which conferred the shisham population into 3 subgroups (Fig. 7) (Table 4). This result depicted the sharing of three gene pools among investigated genotypes (Fig. 8).

Table 4. The Evanno table for 30 shisham genotypes (three provinces) showing maximum $\Delta K=3$

\begin{tabular}{c|c|c|c|c|c|c}
\hline $\mathbf{K}$ & Reps & Mean LnP $(\mathbf{K})$ & St. dev LnP (K) & Ln' (K) $^{\prime}$ & $|\mathbf{L n ”}(\mathbf{K})|$ & $\Delta \mathbf{K}$ \\
\hline 2 & 3 & -4826.833333 & 150.394625 & - & - & - \\
3 & 3 & -3976.766667 & 1.504438 & 850.0666667 & 892.9666667 & 593.555027 \\
4 & 3 & -4019.666667 & 459.283021 & -42.900000 & 118.133333 & 0.257212 \\
5 & 3 & -4180.700000 & 758.598715 & -161.033333 & - & - \\
\hline
\end{tabular}




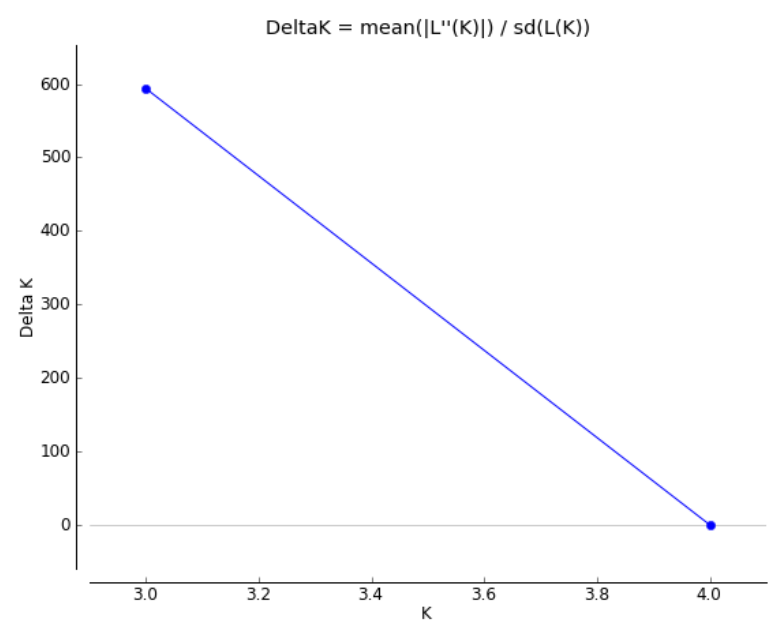

Figure 7. Result of STRUCTUTE HARVESTER in comparison to Evanno table suggest $K$ cluster as $K=3$

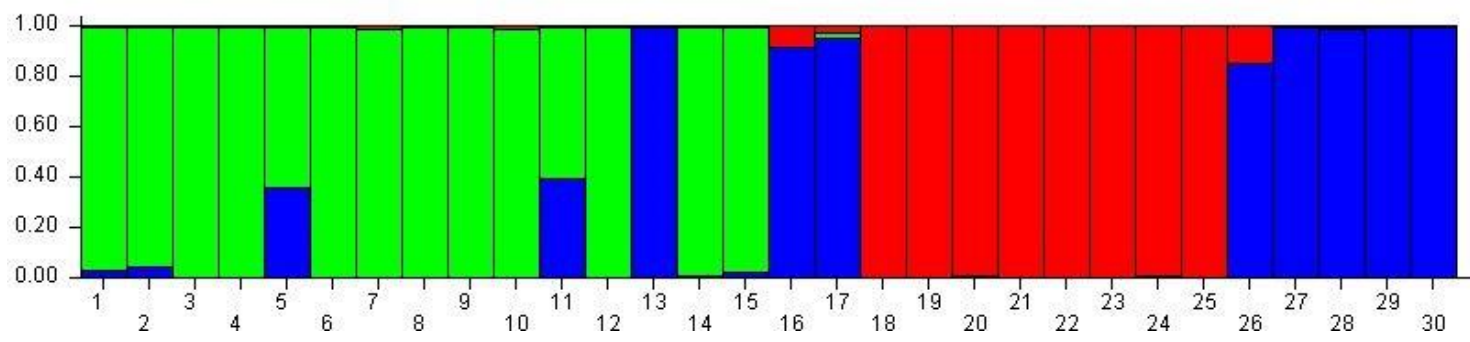

Figure 8. STRUCTURE analysis characterizes the shisham subpopulation into K3, represented in color codes in which each color illustrates the location of genotypes within its respective subgroup. Number on plane axis show the individuals belongs to shisham group and on perpendicular axis show the membership coefficient to sub population group

\section{Discussion}

Genetic diversity has of tremendous importance for any plant or tree species to survive in their natural habitat by providing the knowledge about novel strategies for their conservation. In recent years, DNA molecular markers proved to be a vital strategy for the assessment of inter and intra population interactions as well as variation which greatly contributed in conversation of endanger species (Gudeta, 2018). ISSR regions are present between the SSR motifs that are ubiquitous in genome of higher organism and have ability to discriminate the genotypes (Ijaz and Khan, 2009; Ijaz, 2011).

In the present study, 21 ISSR markers primers produced 337 loci among 30 selected shisham genotypes for which polymorphism percentage was recorded to be $99.41 \%$ accounted for 335 polymorphic loci. Similar study was conducted in Punjab population of Pakistan in which 21 ISSR markers showed 83.32\% polymorphism among 60 selected shisham population (Ijaz et al., 2018). The UPGMA based clustering grouped this population of 30 genotypes in to four clusters and minimum Nei's genetic identity was observed as 0.3273 in SKP3 and KPK P3 while maximum showed to be 0.8487 in KPP2 and NFP2, KPP1 and KPP2, KPK P9 and KPK P10. 
PCoA value was calculated through Drwin6 which showed to be $21.62 \%$ in first coordinate and $19.07 \%$ in second coordinate. However, for PCoA, in the study conducted by Ijaz et al. (2018) revealed the shisham populations of Punjab province, Pakistan showed $16.23 \%$ and $13.83 \%$ in coordinate I and coordinate II respectively. The delta $\mathrm{K}$ value was calculated by using STRUCTURE HARVESTER which was observed as $\mathrm{K}=3$ which revealed that 30 shisham genotypes were sharing three genetic pool, similar results were observed for Punjab shisham population (Ijaz et al., 2018) and for bamboo tree (Nilkanta et al., 2017). As for AMOVA, 99\% and 1\% variation was observed within and among population respectively. Similar results were observed in bamboo (Nilkanta et al., 2017) and pistachio (Meimand et al., 2017).

\section{Conclusion}

Maintenance of genetic diversity of forest trees is also of critical importance worldwide for its preservation, propagation and commercial cultivation. However, in the case of shisham (Dalbergia sissoo) cultivars and accessions there are no identified cultivars and accessions that have been identified as diverse and closely related as well as resistant and susceptible. Genetic diversity assessment of shisham would enable scientists to understand phylogenetic relationships among different genotypes, their geographical distribution and linkage of certain morphological traits with DNA markers linked to the genes controlling them. The information thus obtained may also be helpful in solving the problem of shisham. The research findings will be important in the development towards tagging and identifying $D$. sissoo germplasm on a molecular basis and a practical step for the sustainable management of diseases in shisham.

Acknowledgement. We highly acknowledge "Punjab Agriculture Research Board (PARB), Pakistan" for providing funds under the PARB project no. 952 "Resistance gene analogues based molecular identification for dieback disease resistance in shisham (Dalbergia sissoo)" to conduct this research work.

Conflict of interests. I declare that the submitted manuscript is our own work, which has not been published before and even is not currently being considered for publication elsewhere. And there is no conflict of interests.

\section{REFERENCES}

[1] Bal, P., Panda, P. C. (2018): Molecular characterization and phylogenetic relationships of dalbergia species of eastern India based on RAPD and ISSR analysis. - International Journal of Innovative Science and Technology 3(7): 417-425.

[2] Gudeta, T. B. (2018): Molecular marker based genetic diversity in forest tree populations. - Forestry Research and Engineering: International Journal 2(4): 176-182.

[3] Ijaz, S. (2011): Microsatellite markers: an important fingerprinting tool for characterization of crop plants. - African Journal of Biotechnology 10(40): 7723-7726.

[4] Ijaz, S., Khan, I. A. (2009): Molecular characterization of wheat germplasm using microsatellite markers. - Genetics and Molecular research 8(3): 809-815.

[5] Ijaz, S., Razzaq, H. A., Babar, M., Haq, I. (2018): Assessment of population genetics of shisham (Dalbergia sissoo) based on genetic structure and diversity analysis. International Journal of Biosciences 13(3): 209-222.

[6] Mahmoodnia Meimand, M., Farzad Amirebrahimi, F., Karimi, H. R., Malekzadeh, K., Tajabadipour, A. (2017): Genetic diversity assessment of male and female pistachio genotypes based on ISSR markers. - Journal of Plant Molecular Breeding 5(1): 31-39. 
[7] Nilkanta, H., Amom, T., Tikendra, L., Rahaman, H., Nongdam, P. (2017): ISSR marker based population genetic study of Melocanna baccifera (Roxb.) Kurz: a commercially important bamboo of Manipur, North-East India. - Scientifica 2017. https://doi.org/10.1155/2017/3757238.

[8] Sheng, F., Chen, S.-Y., Tian, J., Li, P., Qin, X., Wang, L., Luo, S.-P., Li, J. (2017): Morphological and ISSR molecular markers reveal genetic diversity of wild hawthorns (Crataegus songorica K. Koch.) in Xinjiang, China. - Journal of Integrative Agriculture 16(11): 2482-2495.

[9] Subedi, G., Sah, C. K., Pokharel, D. K. J., Chaudhary, M. K., Aryal, P., Bhandari, I., Bhandari, R. (2017): Anti-bacterial guided fractionation of Dalbergia sissoo. International Journal of Pharmaceutical Sciences and Research 8(10): 4325-4334.

[10] Tereba, A., Konecka, A., Nowakowska, J.A. (2017): Application of selected molecular markers in studies on forest trees. - Folia Forestalia Polonica 59(2): 146-151.

[11] Wu, W., Chen, F., Yeh, K., Chen, J. (2019): ISSR analysis of genetic diversity and structure of plum varieties cultivated in southern China. - Biology 8(1): 2.

[12] Zaya, D. N., Molano-Flores, B., Feist, M. A., Koontz, J. A., Coons, J. (2017): Assessing genetic diversity for the USA endemic carnivorous plant Pinguicula ionantha RK Godfrey (Lentibulariaceae). - Conservation Genetics 18(1): 171-180. 